\title{
Customer Satisfaction Evaluation for Mobile Commerce Services based On Grey Clustering Relational Method
}

\author{
Jinsong Gao, Jinhui Xu, and Weijun Wang \\ Department of Information Management,Hua Zhong Normal \\ University, Wuhan,430079,China \\ jsgaom@yahoo.com.cn xujinhui1979@yahoo.com.cn \\ wangwj@mail.ccnu.edu.cn
}

\begin{abstract}
Since mobile commerce is a new commerce mode, there is a significant meaning to research on customer satisfaction with its services. This paper evaluates the customer satisfaction with m-commerce services, which adopts ASCI model, uses AHP to identify the weight and adapts grey clustering relational method, and illustrates this method by an example. It makes an exploratory research on the application of the grey comprehensive assessment.
\end{abstract}

\section{Introduction}

As a new commerce mode, mobile commerce (also as m-commerce) means that any information interaction and commerce transaction is conducted via mobile network using mobile communication device such as cell phones, palm computers, portable computers and so on ${ }^{[1]}$.As a new research field, the systematical research on mobile commerce is very few in China and other country didn't start research on it until $2000^{[2]}$.

Literature [3] reviewed 149 mobile commerce articles from 73 journals from 2000 to 2003 and classified them into one of the following five categories: (1)wireless network infrastructure, (2)mobile middleware,(3) wireless user infrastructure, (4)mobile commerce theory and research, and (5)mobile commerce cases and applications. Literature [4] studied the conceptualization and measurement of mobile commerce user satisfaction and pointed out that m-commerce user satisfaction could be used to evaluate whether a m-commerce system was successful and could be evaluated from four aspects: the content quality, appearance, service quality and ease of use. Literature [5] explored the consumer perception of $\mathrm{m}$ commerce application. After reviewing the literature on $\mathrm{m}$-commerce, we find out that the research on m-commerce service customer satisfaction is very few.

Please use the following format when citing this chapter:

Gao, J., Xu, J., Wang, W., 2007, in IFIP International lederation for Information Processing, Volume 251, Integration and Innovation Orient to E-Socicty Volume1, Wang, W. (Eds), (Boston: Springer), pp. 265-273. 
In 1997, Kotler presents that Satisfaction is the consequence of the customer's experiences during various purchasing stages:(a)need rouse,(b)information search, (c) alternatives evaluation,(d)purchase decision, and (e)post-purchase behavior. As for the widely used customer satisfaction model such as ACSI, SWCSIC, ECSI, Kotler pointed out that An abundant literature exists validating the robustness of CSI-like models at the micro level, and have shown that customer satisfaction is a good indicator of a company's future profits in 1991.In the light of the follow-up investigation the FORTURN magazine in USA sponsored on the global top 500 enterprises, there are obviously positive association between the corporation customer satisfaction index and economical and marketing appreciation, which illustrates that if the corporation customer satisfaction index increases 1 percent, the average rate of return property will rise by 11.33 percent ${ }^{[6]}$.As a new commerce mode, if $\mathrm{m}$-commerce means to improve the customer's utilization ratio and acquire the recognition of customer, the key factor is to improve the customer satisfaction thus make them loyal. So the evaluation to m-commerce service customer satisfaction is essential. This paper adopts the American Customer Satisfaction Index Model and use grey comprehensive assessment to appreciate the $\mathrm{m}$-commerce service customer satisfaction in China.

\section{Grey Comprehensive Assessment}

Grey system theory is proposed by professor Deng Julong by the late 1970 s and early 1980s, which can resolve the indefinite problem with inexperienced and incomplete information ${ }^{[7]}$. Grey assessment is a theory and method based on grey theory, which directs at special object to analyze the indices related to the object existed in a system, then assess and describe the object using qualitative grey categories in order to form certain comparative conception and categories for the comprehensive effect and overall level of the system on a higher level.

In general, grey assessment is composed of assessment object, indices, grey category and goal ${ }^{[8]}$. In the light of assessment purpose and requirement, grey assessment can be classified into 4 categories: grey clustering assessment, grey statistic assessment, grey situation assessment and grey relational mode assessment. In the grey comprehensive assessment of practical application, several of the aforementioned categories are combined to evaluate a specific system. This paper adopts grey clustering relational method which combines grey relational mode with grey clustering method.

The basic principle of grey clustering relational method is the following ${ }^{[8]}$ : firstly, use the improved whitening function of grey clustering method to compute the membership grade which every evaluated sample is affiliated to every class, then compute the grey weighted relational grade between the sample and clear comprehensive judgment, lastly, confirm the evaluated object should be classified into a grey class according to the value of the relational grades. 


\section{Evaluation Model of Customer Satisfaction for M-commerce Services}

The steps using grey clustering relational method to evaluate is the following:

\subsection{Confirm the Assessment Indices and Classes}

The American customer satisfaction index model is a country-level customer satisfaction theory model which the system is the most comprehensive and the application effect is the best. Meanwhile, it is a cause-effect relationship model composed of six construct variables ${ }^{[9]}$. It measures the quality of goods and services as experienced by consumers ${ }^{[10]}$ and gauges their actual and anticipated consumption experiences $^{[11]}$. Fig. 1 presents the model.

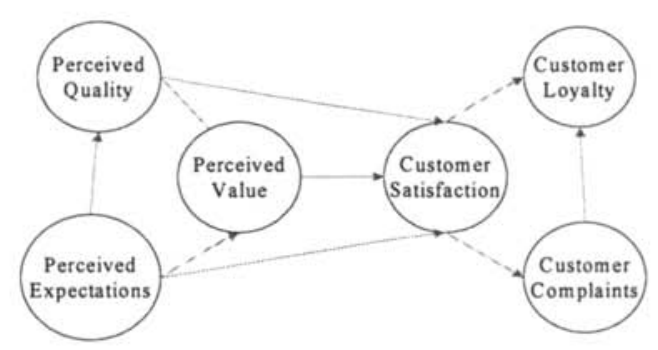

Fig.1. The American customer satisfaction index model

This paper spreads out the structural variables in Fig.1 and forms the multi-level evaluation system as Tab. 1 shows.

Assessment classes adopt five-point Likert scales.Tab.2 shows the assessment standard. About PE,PQ,PV and CS, class 1,2,3,4 and 5 represent great satisfaction, satisfaction, common satisfaction, dissatisfaction and great dissatisfaction separately. For CC, they represent fewer, few, general, many, more separately. As far as CL is concerned, class $1,2,3,4$ and 5 represent great loyalty, loyalty, common loyalty, disloyalty, great disloyalty separately. The value of each class adopts the decimal system which describes the indices qualitatively. As for the same reason, the third assessment standard can be summarized. 
Table 1. Customer Satisfaction Indices for M-commerce Services

The first level the second level the third level

\begin{tabular}{|c|c|c|}
\hline & PFRCEIVED & $\begin{array}{l}\text { YOUR OVERALL EXPECTATION } \\
\text { OF THE QUALITY OF M-COMMERCE } \\
\text { SERVICES (PE } 1)\end{array}$ \\
\hline & $\begin{array}{c}\text { EXPECTATIONS } \\
(\mathrm{PE})\end{array}$ & $\begin{array}{l}\text { Expectation of the extent to which m- } \\
\text { commerce meets your personal } \\
\text { requirements(PE2) }\end{array}$ \\
\hline & & $\begin{array}{l}\text { Your expectation of the reliability of } \\
\text { m-commerce services(PE3) }\end{array}$ \\
\hline & & $\begin{array}{l}\text { Your overall evaluation of the quality } \\
\text { of m-commerce services }(\mathrm{PQ1})\end{array}$ \\
\hline & $\begin{array}{l}\text { Perceived } \\
\text { Quality }\end{array}$ & $\begin{array}{l}\text { Evaluation of the extent to which m- } \\
\text { commerce services meets your personal } \\
\text { requirements( } \mathrm{PQ} 2)\end{array}$ \\
\hline & & $\begin{array}{l}\text { Your evaluation of the reliability of } \\
\text { m-commerce services (PQ3) }\end{array}$ \\
\hline & Perceived & $\begin{array}{l}\text { Your evaluation of the quality of m- } \\
\text { commerce services if given the prices you } \\
\text { pay (PV1) }\end{array}$ \\
\hline CUSTOMER & $\begin{array}{l}\text { value } \\
\text { (PV) }\end{array}$ & $\begin{array}{l}\text { Your evaluation of the price of m- } \\
\text { commerce services if given the quality } \\
\text { you receive(PV2) }\end{array}$ \\
\hline $\begin{array}{l}\text { INDICES } \\
\text { INA }\end{array}$ & Customer & $\begin{array}{l}\text { The extent to which the actual } \\
\text { perception of m-commerce services have } \\
\text { fallen short or exceed your overall } \\
\text { expectation (CS1) }\end{array}$ \\
\hline & satisfaction(CS) & $\begin{array}{l}\text { How close are the actual perception of } \\
\text { m-commerce to your ideal m-commerce } \\
\text { services (CS2) }\end{array}$ \\
\hline & $\begin{array}{c}\text { Customer } \\
\text { complaints }(\mathrm{CC})\end{array}$ & $\begin{array}{l}\text { Official or unofficial complaints } \\
\text { about m-commerce services (CC1) }\end{array}$ \\
\hline & & $\begin{array}{l}\text { How likely you purchase the same m- } \\
\text { commerce service repeatedly (CL1) }\end{array}$ \\
\hline & Customer & $\begin{array}{l}\text { How likely you recommend the m- } \\
\text { commerce service to your circle of } \\
\text { acquaintances (CL2) }\end{array}$ \\
\hline & $\begin{array}{l}\text { loyalty } \\
\text { (CL) }\end{array}$ & $\begin{array}{l}\text { The range of price increases the m- } \\
\text { commerce services provider adopts you } \\
\text { can endure (CL3) }\end{array}$ \\
\hline & & $\begin{array}{l}\text { The range of price decreases the m- } \\
\text { commerce services competitor adopts you } \\
\text { can resist (CL4) }\end{array}$ \\
\hline
\end{tabular}

Table 2. Standard of M-commerce Services

\begin{tabular}{|c|c|c|c|c|c|c|}
\hline Class & $\mathrm{PE}$ & $\mathrm{PQ}$ & PV & $\mathrm{CS}$ & $\overline{C C}$ & $\mathrm{CL}$ \\
\hline 1 & $\begin{array}{c}8- \\
10\end{array}$ & $\begin{array}{r}8 \\
10\end{array}$ & $8-10$ & $\begin{array}{c}8- \\
10\end{array}$ & $0-2$ & $\begin{array}{c}8- \\
10\end{array}$ \\
\hline 2 & $6-8$ & $6-8$ & $6-8$ & $6-8$ & $2-4$ & $6-8$ \\
\hline 3 & $4-6$ & $4-6$ & $4-6$ & $4-6$ & $4-6$ & $4-6$ \\
\hline 4 & $2-4$ & $2-4$ & $2-4$ & $2-4$ & $6-8$ & $2-4$ \\
\hline 5 & $0-2$ & $0-2$ & $0-2$ & $0-2$ & $\begin{array}{c}8 \\
10\end{array}$ & $0-2$ \\
\hline
\end{tabular}




\subsection{Constructing Whitening Function}

In order to make the membership existed between the whitening function and the assessment classes, the lower semi-trapezoid structure of whitening function in grey clustering method need to be improved. Three basic figures are shown in Fig. $2^{[8]}$.

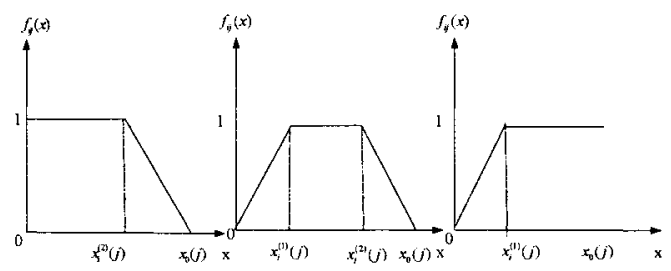

(a) (b)

(c)

Fig.2. Three whitening function of grey clustering relational method

$x_{k}(j)$ represents the actual value of the index $\mathrm{j}$ of the kth assessment sample. In fig. $2,\left[x_{i}^{(1)}(j), x_{i}^{(2)}(j)\right]$ is the standard interval that the assessment index $\mathrm{j}$ is affiliated to class i. $x_{0}(j)={ }_{\max _{i}^{(2)}(j)}, f_{i j}(x)$ is the whitening function that the assessment index $\mathrm{j}$ is affiliated to class $\mathrm{i}$.

Three expressions can be used to calculate the three aforementioned whitening function showed in fig.2, which are as follows:

The first equation (see Fig.2a, which is applicable to the situation of $x_{i}^{(1)}(i)=0$ ):

$$
f_{z y}(x)=\left\{\begin{array}{c}
1, \text { for } 0 \leq x \leq x_{i}^{(2)}(j) \\
\left(x-x_{0}(j)\right) /\left(x_{i}^{(2)}(j)-x_{0}(j)\right), \text { for } x_{i}^{(2)}(j) \leq x \leq x_{0}(j)
\end{array}\right.
$$

The second equation (Fig.2b, which is applicable to the situation of $\left.x_{i}^{(1)}(j), x_{i}^{(2)}(j) \neq 0\right)$ :

$$
f_{i j}(x)=\left\{\begin{array}{c}
\frac{1}{x_{i}^{(1)}(j)} x, \text { for } 0 \leq x \leq x_{i}^{(1)}(j) \\
1 . f o r x_{i}^{(1)}(j) \leq x \leq x_{i}^{(2)}(j) \\
\left(x-x_{0}(j)\right) /\left(x_{i}^{(2)}(j)-x_{0}(j)\right), \text { for } x_{i}^{(2)}(j) \leq x \leq x_{0}(j)
\end{array}\right.
$$

The third equation (Fig.2c, which is applicable to the situation of $\left.x_{i}^{(2)}(j)=x_{0}(j)\right)$ :

$$
f,(x)=\left\{\begin{array}{c}
\frac{1}{x ! 1(j)} x, \text { for } 0 \leq x \leq x,+(j) \\
1, f \circ r x ; \prime(j) \leq x \leq x_{0}(j)
\end{array}\right.
$$




\subsection{The Attribute Weights of Assessment Indices}

Since the different contribution of each index to the assessment object, it will be unfair to adopt the equal-weight method. This paper determines attribute weights using AHP. The calculating process is as follows:

(1) Judge the relative importance of each assessment index and establish judgment matrix $\mathrm{A}$.

(2) Carry out consistency test for A. The equation is expressed as follows:

$$
C R=C I / R I
$$

Where $C I$ (consistency index $)=\left(\lambda_{\max }-\mathrm{k}\right) /(\mathrm{k}-1), \mathrm{k}$ represents the number of the assessment indices and $\mathrm{RI}$ (random consistency index) average index of randomly generated weights that can be obtained through looking up the table created by Saaty. If $\mathrm{CR}<0.1$,pass the test, otherwise need to adjust the matrix $A$ and carry out another consistency test till pass it.

(3) Calculate the eigenvector corresponding to $\lambda_{\max }$ (the maximum eigenvalue) of the judgment matrix A, namely, the weights of the indices are confirmed.

\subsection{Calculating Grey Relational Grade}

Make $y_{k i}(j)=f_{i j}\left(x_{k}(j)\right)$, namely, the membership grade (or whitening function) of the index $j$ of the assessment object $k$ to the class $i$ If $y_{k j}=\left(y_{k i}(1), y_{k i}(2), y_{k i}(3), \cdots, y_{k i}(n)\right)=(1,1,1, \cdots, 1)$, the assessment object $\mathrm{k}$ can be evaluated as class $\mathrm{i}$, and call $y_{k i}$ a clear comprehensive judgment.

Make $y_{0 i}$ be a clear comprehensive judgment and let it to be reference sequence, then calculate its relational grade $r_{k i}$ with $y_{k i}$. The equation is expressed as follows:

$$
r_{k j}=\sum_{j=1}^{n} w_{k j} \varepsilon \ldots(j)
$$

where

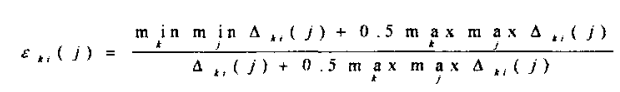

$\Delta_{k i}(j)=\left|y_{k i}(j)-1\right|$ 


\subsection{Calculating Multi-level Relational Grade and Evaluating Comprehensively}

After obtaining the relational grade of a level, relational grade of the level above it can be calculated through equation 3 .

$$
R_{,}=\sum_{k-1}^{9} w_{k} r_{k}
$$

Where $R_{s}=\max _{i} R_{i}$, thus can evaluate the class of the assessment object to be $\mathrm{s}$.

\section{Example Analysis}

As for the second-level indices $P E, P Q, P V, C S, C L$ and the third-level indices PE1, PE2, PE3, PQ1, PQ2, PQ3, PV1, PV2, CS1, CS2, CL1 CL2, CL3, they have same interval value of each class standard, so they have same whitening functions which are presented as follows.

The first class(Fig.2c):

$$
f_{1},(x)=\left\{\begin{array}{l}
\frac{1}{8} x, \text { for } 0 \leq x \leq 8 \\
1, \text { for } 8 \leq x \leq 10
\end{array}\right.
$$

The second, third and forth class(Fig.2b):

$$
\begin{gathered}
f_{1},(x)=\left\{\begin{array}{c}
\frac{1}{6} x, \text { for } 0 \leq x \leq 6 \\
1, \text { for } 6 \leq x \leq 8 \\
5-0,5 x, \text { for } 8 \leq x \leq 10
\end{array} f_{3 ;}(x)=\left\{\begin{array}{c}
\frac{1}{4} x, \text { for } 0 \leq x \leq 4 \\
1, \text { for } 4 \leq x \leq 6 \\
2,5-25 x, \text { for } 6 \leq x \leq 10
\end{array}\right.\right. \\
f_{4},(x)=\left\{\begin{array}{c}
\frac{1}{2} x, \text { for } 0 \leq x \leq 2 \\
1, \text { for } 2 \leq x \leq 4 \\
\frac{5}{3}-\frac{1}{6} x, \text { for } 4 \leq x \leq 10
\end{array}\right.
\end{gathered}
$$

The fifth class(Fig.2a):

$$
f_{5},(x)=\left\{\begin{array}{c}
1, \text { for } 0 \leq x \leq 2 \\
1.25-0.125 x, \text { for } 2 \leq x \leq 10
\end{array}\right.
$$

The whitening functions of the second-level index $\mathrm{CC}$ and the third-level index $\mathrm{CC} 1$ are contrary to the above. Namely, their whitening functions of the first class is the fifth class above, the second the forth, the third the third, ..., the fifth the first.

The actual value of each third level index can be obtained through the way of questionnaire investigation. If there are 200 valid questionnaire, the value of the third-level indices can be computed by the equal weights method. For example, if $q_{j}$ represents the answer of the jth respondent, the actual value of PQ1 equal $(1 / 200)$ * $\left(\mathrm{q}_{1}+\mathrm{q}_{2}+\cdots+\mathrm{q}_{200}\right)$.

Given the actual values of the third level indices is showed in Tab.3. 
Table 3. The Data of Third-level Indices of Customer Satisfaction

\begin{tabular}{|l|l|l|l|l|l|l|l|l|l|l|}
\hline PE1 & PE2 & PE3 & PQ1 & PQ2 & PQ3 & PV1 & PV2 & CS1 & CS2 & CC1 \\
\hline 7.3 & 8.6 & 9 & 5.2 & 6 & 8.2 & 4.5 & 5 & 7.5 & 5.4 & 3 \\
\hline CL1 & CL2 & CL3 & CL4 & & & & & & & \\
\hline 6.5 & 4.6 & 1.7 & 2.3 & & & & & & & \\
\hline
\end{tabular}

Determine the weight of each index using AHP, see Tab.4.

Table 4. The Weights of the Third-level and Second-level Indices of Customer Satisfaction

\begin{tabular}{|l|l|l|l|l|l|l|l|}
\hline PE1 & PE2 & PE3 & PQ1 & PQ2 & PQ3 & PV1 & PV2 \\
\hline 0.325 & 0.384 & 0.291 & 0.312 & 0.363 & 0.325 & 0.56 & 0.44 \\
\hline CS1 & CS2 & CC1 & CL1 & CL2 & CL3 & CL4 & \\
\hline 0.65 & 0.35 & 1 & 0.32 & 0.12 & 0.3 & 0.26 & \\
\hline PE & PQ & PV & CS & CC & CL & & \\
\hline 0.075 & 0.225 & 0.2 & 0.308 & 0.105 & 0.087 & & \\
\hline
\end{tabular}

Calculate the whitening functions value of the third-level indices' membership to each class. As follows:

$$
\begin{aligned}
& \text { PE: } y_{11}=(0.9125,1,1), y_{12}=(1,0.7,0.5), \quad y_{13}=(0.675,0.35,0.25) \text {, } \\
& y_{14}=(0.45,0.2333,0.1667), \quad y_{15}=(0.3375,0.175,0.125) \\
& \mathrm{PQ}: y_{21}=(0.65,0.75,1), y_{22}=(0.8667,1,0.9), \quad y_{23}=(1,1,0.45) \text {, } \\
& y_{24}=(0.8,0.6667,0.3), \quad y_{25}=(0.6,0.5,0.225) \\
& \text { PV: } y_{31}=(0.5625,0.625), y_{32}=(0.9,0.8333), \quad y_{33}=(1,1) \text {, } \\
& y_{34}=(0.9167,0.8333), \quad y_{35}=(0.6875,0.625) \\
& \text { CS: } y_{41}=(0.9375,0.675), y_{42}=(1,0.9), \quad y_{43}=(0.625,1) \text {, } \\
& y_{44}=(0.4167,0.7667), \quad y_{45}=(0.3125,0.575) \\
& \text { CC: } y_{51}=(0.875), y_{52}=(1), \quad y_{53}=(0.75), \quad y_{54}=(0.5), \quad y_{55}=(0.375) \\
& \text { CL: } y_{61}=(0.8125,0.575,0.2125,0.2875), y_{62}=(1,0.7667,0.2833,0.3833) \text {, } \\
& y_{63}=(0.875,1,0.425,0.575), \quad y_{64}=(0.5833,0.9,0.85,1), y_{65}=(0.4375,0.675 \text {, }
\end{aligned}
$$
$1,0.9625)$

According equation 2, the relational grade of the second-level indices to each class can be calculated, which are shown in Tab.5.

Table 5. The Relational Grade of the Second-level Indices to Each Class

\begin{tabular}{|c|c|c|l|l|l|l|}
\hline $\begin{array}{c}\text { Second level } \\
\text { indices }\end{array}$ & PE & PQ & \multicolumn{1}{|c|}{ PV } & \multicolumn{1}{|c|}{ CS } & CC & CL \\
\hline $\mathbf{1}$ & 0.9409 & 0.7122 & 04906 & 0.7527 & 0.4406 & 0.4670 \\
\hline $\mathbf{2}$ & 0.6722 & 0.8445 & 0.7381 & 0.9236 & 1 & 0.5882 \\
\hline $\mathbf{3}$ & 0.4116 & 0.8068 & 1 & 0.6750 & 0.6 & 0.6003 \\
\hline $\mathbf{4}$ & 0.3723 & 0.5337 & 0.781 & 0.4952 & 0.4545 & 0.7373 \\
\hline $\mathbf{5}$ & 0.3593 & 0.4497 & 0.5636 & 0.4303 & 0.4118 & 0.7483 \\
\hline
\end{tabular}

According equation 3 , the relational grade of the customer satisfaction index to each class can be calculated. The result is as follows.

$\mathrm{R}=(0.6477,0.8287,0.7355,0.5686,0.4817)$

According the result, the customer satisfaction index of this example is classified into class 2, that is, satisfaction. 


\section{Conclusion}

This paper makes an exploratory research on evaluating m-commerce customer satisfaction, which adopts ASCI model, uses AHP to determine the weight and adapts grey clustering relational method .This method is simple and easy to carry out, what is more, the calculating procedure can be realized by programming in $\mathrm{c}$. By evaluating the customer satisfaction, it will help consumers to make better purchasing decisions and help service providers to understand the consumer behavior and know their strengths and weaknesses so that they can implement a serious of effective measures ${ }^{[12]}$. Despite its some advantages, this study has a key limitation. For the construct variables in ASCI model are general, it is better to combine the third-level indices in questionnaire with the practical application to be further spread out to be the forth-level indices in order to make questionnaire investigation more accurate.

\section{References}

1. Y. F. Yuan, Y. W. Wang and Z. C. Xu , Mobil Commerce, Tsinghua University Press, Beijing (2006).

2. W. Huang, R. D. Wang and N. Shi, "Review Study on Mobile Commerce", Application of Computer Research , (1), 3-15(2006).

3. E. W. T. Ngai and A. Gunasekaran, "A Review for Mobile Commerce Research and Application", Decision Support Systems, 43(1),3-15(2007).

4. Y. S. Wang, Y. W. Liao, "The Conceptualization and Measurement of Mcommerce User Satisfaction”, Computers in Human Behavior, 23(1), 381-398 (2007).

5. P.Mahatanankoon, H. Joseph Wen, and B. Lim, "Consumer-based Mcommerce: exploring Consumer Perception of Mobile Applications", Computer Standards \& Interfaces, 27(4), 347-357(2005).

6. L. R. Gan, B. Ma and Y. M. Li, "Evaluation of the User Satisfaction Level on Four Famous Databases Websites", Journal of the China Society For Scientific and Technical Information, 23(5), 524-530(2004).

7. J. L. Deng, The Foundation of Grey System Theory, Huazhong University of Science and Technology Press, Wuhan (2002).

8. X. P. Xiao, Z. P. Song and F. Li, The Foundation and Application of Grey Technology, Science Press, Beijing (2005).

9. Q. Luo and Z. Q. Fang, "An Analysis of Common Research Model of Customer Satisfaction and Their Strengths and Weaknesses", Journal of Guizhou College of Finance and Economics, (6), 14-17(2002).

10. C. Fornell, M. D. Johnson, E. W. Anderson, J. Cha and B .E. Bryant., "The American Customer Satisfaction Index: Nature, Purpose, and Findings", Journal of Marketing , 60(4), 7-18 (1996).

11. E. W. Anderson and C. Fornell, "Foundations of the American Customer Satisfaction Index", Total Quality Management \& Business Excellence, 11(7), 869882(2000).

12. http://cbrc.em.tsinghua.edu.cn/ReadNews.asp?NewsID $=830,2007,04,10$. 